\title{
Antibiotic resistance in aerobic bacterial isolates from infected diabetic foot ulcers in North Eastern Tanzania: an urgent call to establish a hospital antimicrobial stewardship committee
}

\author{
Ahmed Shabhay ${ }^{1,2,3}$, Pius Horumpende ${ }^{1,3,4,11}$, Martin Mujuni ${ }^{5,7}$, Edna-Joy Munisi ${ }^{8}$, Stephen \\ Mshana $^{6}$, Zarina Shabhay ${ }^{9}$, Andrew Mganga ${ }^{7}$, Kondo Chilonga ${ }^{1,2}$, David Msuya ${ }^{1,2}$, Jaffu O. \\ Chilongola $^{4,11}$, Jeff Van Baal ${ }^{10,12}$, Samwel Chugulu ${ }^{1,2}$
}

\author{
${ }^{1}$ Department of General Surgery, Kilimanjaro Christian Medical University College, Moshi, Tanzania \\ ${ }^{2}$ Department of General Surgery, Kilimanjaro Christian Medical Centre, Moshi, Tanzania \\ ${ }^{3}$ Institute of Infectious Diseases and Research, Lugalo Military College of Medical Sciences (MCMS) and General Military \\ Hospital (GMH), Dar es Salaam, Tanzania. \\ ${ }^{4}$ Department of Biochemistry and Molecular Biology, Kilimanjaro Christian Medical University College, Moshi, Tanzania. \\ ${ }^{5}$ Department of Internal Medicine, Kagera Regional and Consultant Hospital, Bukoba, Tanzania \\ ${ }^{6}$ Department of Microbiology and Immunology, Catholic University of Health and Allied Sciences (CUHAS), Mwanza, \\ Tanzania. \\ ${ }^{7}$ Department of Public Health, Kilimanjaro Christian Medical University College, Moshi, Tanzania \\ ${ }^{8}$ Department of Internal Medicine, Mount Meru Regional and Consultant Hospital, Arusha, Tanzania \\ ${ }^{9}$ Department of Neuro-Surgery, Muhimbili Orthopedic Institute Dar es Salaam \\ ${ }^{10}$ ZGT Academy, Hospital Group Twente, Almelo/Hengelo, The Netherlands. \\ ${ }^{11}$ Kilimanjaro Christian Research Institute (KCRI) Moshi \\ ${ }^{12}$ Cardiff University, Cardiff, Wales, UK
}

Received: 10 August 2021

Revised: 09 September 2021

Accepted: 13 September 2021

\section{*Correspondence:}

Dr. Ahmed Shabhay,

Email: ahmedshabio84@gmail.com

Copyright: (C) the author(s), publisher and licensee Medip Academy. This is an open-access article distributed under the terms of the Creative Commons Attribution Non-Commercial License, which permits unrestricted non-commercial use, distribution, and reproduction in any medium, provided the original work is properly cited.

\section{ABSTRACT}

Background: Diabetic foot ulcers (DFU) is among major health problems which impact the socio economic burden globally. We aimed at assessing the susceptibility pattern of antimicrobials in DFU infections among patients admitted in the surgical department at Kilimanjaro Christian Medical Centre (KCMC).

Methods: This descriptive cross-sectional study was conducted from September 2018 through March 2019. Pus swabs were collected on the first day of admission by deep wound swabbing after irrigation with normal saline solution. KirbyBauer method was done according to the Clinical and Laboratory Standard Institute (CLSI) guidelines.

Results: Sixty diabetic ulcer patients had 62 bacterial isolates. Majority of the isolates were gram negative 49/62 (79.03\%). The most common isolate was Escherichia coli 15/62 (24.19\%) followed by Pseudomonas aeruginosa 14/62 (22.58\%), Proteus mirabilis 8/62 (12.9\%) and Staphylococcus aureus 5/62 (8.06\%). Klebsiella pneumoniae, coagulase negative Staphylococcus, Proteus vulgaris, and Streptococcus pyogenes each contributed 4/62 (6.25\%) isolates. Of the 49/62 (79.3\%) gram negative isolates, $8 / 49$ (16.33\%) were mono resistant, 30/49 (61.22\%) were multiresistant, and $11 / 49(22.45 \%)$ were susceptible. Of the multi-resistant isolates, E. coli 12/15 (80.00\%), and P. aeruginosa $7 / 14$ $(50.00 \%)$ were predominant. A total of $39 / 62(62.90 \%)$ isolates in patients contributed to poorer outcomes including loss of body part. Patients with ulcers infected by P. aeruginosa 11/39 $(28.21 \%)$ had the highest number of surgical removal of body parts followed by E. coli $8 / 39(20.51 \%)$. Gram negative bacteria were highly susceptible to amikacin $91.18 \%$, meropenem $93.33 \%$ and imipenem $95.24 \%$. Isolates susceptibility to ceftriaxone was $32 \%$.

Conclusions: Amikacin, meropenem and imipenem can be safely used as broad-spectrum antimicrobials in DFU. The standard of care remains culture and sensitivity of isolated microorganisms in combating diabetic foot ulcers infections.

Keywords: Antibiotic resistance, Diabetic foot ulcers, Multiple bacterial infection, Gram negative aerobes, Tanzania 


\section{INTRODUCTION}

Diabetic patients with diabetic foot infections cause significant health problems as they reduce quality of life, lead to amputations and are associated with increased cost of health services. ${ }^{1-3}$ This is exacerbated by the presence of resistant bacteria to antimicrobial agents (AMR). Thus, antibiotic resistance is considered a serious problem in medical-surgical care set-ups. ${ }^{4}$ Diabetic patients are considered a high-risk group for development of surgical site infection as they are mostly immune suppressed., Prompt actions to reduce antibiotic resistance development are needed to protect the current antibiotics that are still working. ${ }^{7}$

It is estimated that approximately 700,000 people die each year due to drug resistant pathogens. Projections show that AMR pathogens will cause about 10 million deaths each year by $2050 .^{7}$ In many cases AMR basically reflects irrational use of antibiotics with ultimate increase in selection pressure favoring emergence of drug resistant bacteria. ${ }^{8}$ The effects of AMR on patients and health care systems are prolonged hospital stay, need for institutional care, high treatment costs and poor functionality., Furthermore, in the context of diabetes AMR leads to disarticulation or amputation and high both short- and long-term morbidities. ${ }^{10}$ Besides these, AMR has been shown to be associated with significant distress to the patient and the family. ${ }^{11,12}$

It is important that empirical antibiotic prescription be guided by local susceptibility patterns data to reduce inappropriate antimicrobial use. ${ }^{13}$ No data exists in Sub Saharan African countries, on the epidemiology of AMR among diabetic patients with DFU. This is due to lack of standardized diagnosis, absence of effective surveillance system and uniform notification system in sub-Saharan African countries. ${ }^{14-16}$ Tanzanian national action plan on antimicrobial resistance addressing actions in combat AMR was launched in August 2017. ${ }^{17}$ It aims, among other things, to insist on rational use of antibiotics by targeted prescribing. However, local susceptibility patterns on diabetic wounds remain undocumented leading to empiric antibiotic prescribing. Local susceptibility data may aid in controlling irrational use of antimicrobials and mitigate AMR in Tanzania. Earlier studies have put forward Staphylococcus aureus, Klebsiella pneumonia and Escherichia coli to be the most prominent isolated bacteria among DFU patients. ${ }^{18,19}$

One study showed the majority of resistant strains of methicillin resistant Staphyloccocus aureus of 35\%, K. pneumoniae and E. coli resistance rates of $38.5 \%$ and $29.3 \%$ for ceftriaxone respectively; and that majority of the invasive infections were gram negative bacteria. ${ }^{20}$ Little is known on antibiotic resistance among diabetic patients with infected foot ulcer in Tanzania. Based on limited available antimicrobial resistance data on diabetic ulcers in resource limited settings it is obvious that the empiric management of diabetic foot ulcer may be ineffective and more costly to an individual and entire health system. Therefore, we aimed at identifying bacterial aetiologies, their sensitivity patterns on the commonly prescribed antibiotics among patients with infected DFU in surgical wards of KCMC, a tertiary and a University teaching hospital in Moshi municipality, North eastern Tanzania.

\section{METHODS}

\section{Study settings, design and population}

The study was done in Kilimanjaro Christian Medical Centre (KCMC). KCMC is a consultant, teaching and referral hospital serving a population of over 11 million people from northern and central regions of Tanzania. This was a hospital based descriptive cross- sectional study conducted among diabetic foot patients admitted in the general surgery department at KCMC for a period of 6 months from September 2018 through March 2019.

\section{Clinical laboratory procedures}

Pus specimens from in - patients were collected on the first day of hospital admission by deep wound swabbing after the wounds were irrigated with normal saline solution. The specimens were submitted to the KCMC clinical laboratory in Stuart Transport medium for testing. The specimens were aerobically subjected to culture on Blood Agar and Mac-Conkey agar plates. Bacterial isolates were gram stained. Susceptibility tests for the isolated pathogens were performed by disc diffusion (Kirby-Bauer) method according to the Clinical and Laboratory Standards Institute (CLSI) guidelines. Patients antibiotic regimes were then tailored as per their pus swab culture and sensitivity results.

\section{Clinical management of patients}

Enrolment in the study required the patient to be above 18 years, be diagnosed with diabetes and an infected ulcer below the malleolus. A clinical diagnosis of an infected ulcer was based upon signs of purulent discharge, pain, erythema, warmth and induration. Prior pus swab culture and sensitivity results, patients were instituted on broad spectrum antibiotics and switched accordingly post sensitivity results. Daily wound dressing with normal saline was done with closed method of wound dressing with gauze. Serial dressing with sharp dedridement was done to remove sloughs with dead tissues. Non healing ulcers with deep tissues destruction and infection, involved limbs underwent either transtibial or femoral amputation.

\section{Data management}

Data were abstracted from patients' files using a structured questionnaire, transferred and processed using STATA version 14.0 (Stata Corp, College Station, TX, USA). Data checking for inconsistency or missing values, formatting variables like dates/time, variables transformation, 
generating, recoding variables, duplicate entries or any unusual values (outliers) were identified and removed prior to analysis. Data analysis was based on complete case analysis.

\section{Data analysis}

Data were descriptively analysed. Categorical variables were summarized as frequencies/proportions.

\section{Ethical considerations}

Ethical clearance was obtained from Kilimanjaro Christian Medical University College Research and Ethical Committee (CREC) certificate number 2366. Confidentiality was ensured in that no personal identifying information was written in the data capture or database. Written informed consent to participate in the study was obtained from study participants. Participants were clearly made to understand that no participation in the study would in no way jeopardize clinical management in the ward.

\section{RESULTS}

Sixty diabetic ulcer patients had 62 bacterial isolates from 12 bacterial species. Majority were gram negative, contributing to almost two thirds 49 (79.03\%) of all isolates. The most common isolate was Escherichia coli 15 (24.19\%) followed by Pseudomonas aeruginosa 14 (22.58\%), Proteus mirabilis 8 (12.9\%) and Staphylococcus aureus 5 (8.06\%). Klebsiella pneumoniae, coagulase negative Staphylococcus, Proteus vulgaris, and Streptococcus pyogenes each contributed 4 (6.25\%) isolates. The rest of isolates including Acinetobactor spp, Citrobacter spp, Morganella morgani, non-fermenting gram-negative bacilli each contributed 1 (1.61\%) isolate (Figure 1).

Of the $13(20.97 \%)$ isolates of gram positive, $2(15.38 \%)$ were mono-resistant, $3(23.08 \%)$ were multidrug resistant to the antimicrobials tested, and $8(61.54 \%)$ were susceptible. Of the $49(79.3 \%)$ gram negative isolates, 8 $(16.33 \%)$ were mono-resistant, 30 (61.22\%) were multidrug resistant and $11(22.45 \%)$ were susceptible (Table 1). Of the 60 patients in the study, 47 (78.33\%) had single bacterial isolate, $7(11.67 \%)$ had multiple bacterial isolates and $6(13.04 \%)$ with no bacterial growth (Figure 2). Considering individual isolates with multiple antibiotic resistance, Escherichia coli 12/15 (80.00\%) and Pseudomonas aeruginosa $7 / 14$ (50.00\%) had the highest levels of multiple antibiotic resistance to the antimicrobials tested. More than half 33/62 (53.23\%) of the total isolates had multiple antibiotic resistance (Table 2).

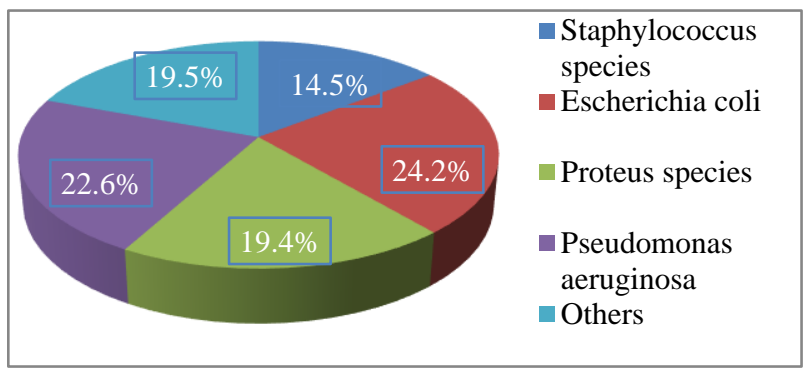

Figure 1: The distribution of clinical isolates $(\mathrm{N}=62)$.

A total of 15 isolates were tested against meropenem where $14(93.33 \%)$ were sensitive. For imipenem 21 isolates were tested whereby $20(95.23 \%)$ were sensitive. Isolates tested against amikacin were 34 whereby $27(79.41 \%)$ were susceptible. With regard to gentamicin 40 isolates were tested where $22(55.00 \%)$ were susceptible. Ciprofloxacin was tested against 34 isolates whereby 16 (47.06\%) were sensitive. Ceftriaxone, a common antibiotic in used in the ward, was tested against 25 isolates, whereby $8(32.00 \%)$ were sensitive and $17(68.00 \%)$ were resistant. A combination of amoxicillin and clavulanic acid was tested against 29 isolates whereby $8(27.56 \%)$ were sensitive (Table 3).

Thirty-nine out of sixty-two $(62.90 \%)$ isolates contributed to poorer outcomes including loss of a body part. Patients with ulcers infected by Pseudomonas aeruginosa 11/39 $(28.21 \%)$ had the highest number of surgical removal of body parts followed by Escherichia coli 8/39 (20.51\%) (Table 4).

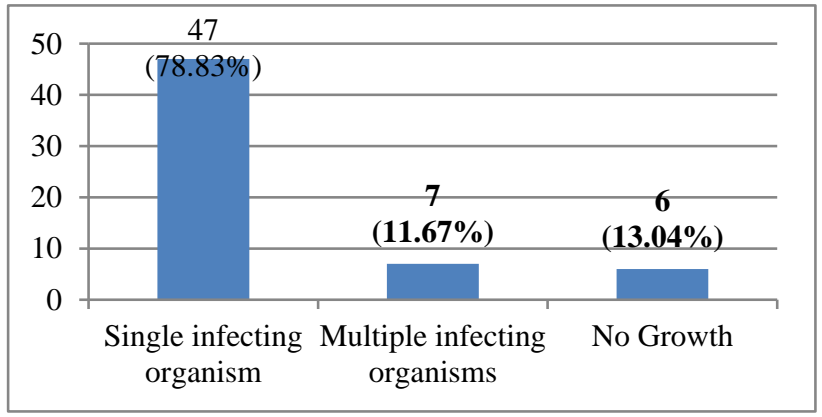

Figure 2: Number of patients with single or multiple microbial isolates $(\mathrm{N}=60)$.

Table 1: Gram staining status and extent of resistance.

\begin{tabular}{|c|c|c|c|}
\hline \multirow{2}{*}{ Gram status } & \multicolumn{3}{|l|}{ Drug resistance } \\
\hline & §Mono-resistant (N (\%)) & Multidrug resistant $(\mathrm{N}(\%))$ & Susceptible (N (\%)) \\
\hline Gram negative & $8(16.33)$ & $30(61.22)$ & $11(22.45)$ \\
\hline Gram positive & $2(15.38)$ & $3(23.08)$ & $8(61.54)$ \\
\hline Total & $10(16.13)$ & $33(53.23)$ & $19(30.65)$ \\
\hline
\end{tabular}

§Mono-resistance refers to bacteria spp. with resistance to only one of the tested antibiotics 
Table 2: Microbial isolates compared by resistance to a single or multiple drugs.

\begin{tabular}{|c|c|c|c|}
\hline \multirow{2}{*}{ Isolate } & \multicolumn{3}{|l|}{ Drug resistance } \\
\hline & §Monoresistant (N (\%)) & Multidrug resistant (N (\%)) & Susceptible (N (\%)) \\
\hline Other species & $1(8.33)$ & $8(66.67)$ & $3(25.00)$ \\
\hline Escherenchia coli & $3(20.00)$ & $12(80.00)$ & - \\
\hline Proteus species & $3(25.00)$ & $5(41.67)$ & $4(33.33)$ \\
\hline Pseudomonas aeruginosa & $2(14.29)$ & $7(50.00)$ & $5(35.71)$ \\
\hline Staphylococcus species & $1(11.11)$ & $1(11.11)$ & $7(77.78)$ \\
\hline Sterile growths & - & - & $6(100.00)$ \\
\hline Total $=62$ & $10(16.13)$ & $33(53.23)$ & $25(36.76)$ \\
\hline
\end{tabular}

$\S$ Mono-resistance refers to bacteria spp. with resistance to only one of the tested antibiotics

Table 3: Aetiologies and the sensitivity patterns of bacterial clinical isolates.

\begin{tabular}{|c|c|c|c|c|c|c|c|c|c|c|c|c|c|c|c|c|c|c|c|c|}
\hline \multirow{2}{*}{$\begin{array}{l}\text { Clinical } \\
\text { isolate }\end{array}$} & \multicolumn{4}{|c|}{$\begin{array}{l}\text { Staphylococcus } \\
\text { species }\end{array}$} & \multicolumn{4}{|c|}{ Escherichia coli } & \multicolumn{4}{|c|}{ Proteus species } & \multicolumn{4}{|c|}{$\begin{array}{l}\text { Pseudomonas } \\
\text { aeruginosa }\end{array}$} & \multicolumn{4}{|c|}{ Others } \\
\hline & $\mathbf{S}$ & $\mathbf{R}$ & & & $\mathbf{S}$ & & $\mathbf{R}$ & & $\mathbf{S}$ & & $\mathbf{R}$ & & $\mathbf{S}$ & & $\mathbf{R}$ & & $\mathbf{S}$ & & $\mathbf{R}$ & \\
\hline Antibiotic & $\mathbf{N}$ & $\%$ & $\mathbf{N}$ & $\%$ & $\mathbf{N}$ & $\%$ & $\mathbf{N}$ & $\%$ & $\mathbf{N}$ & $\%$ & $\mathbf{N}$ & $\%$ & $\mathbf{N}$ & $\%$ & $\mathbf{N}$ & $\%$ & & $\%$ & $\mathbf{N}$ & $\%$ \\
\hline Ceftriaxone & 1 & 11.1 & 1 & 5.6 & 2 & 22.2 & 9 & 50 & 5 & 55.6 & 5 & 27.8 & 1 & $\begin{array}{l}11 \\
.1\end{array}$ & 2 & 11.1 & 0 & 0 & 1 & 5.6 \\
\hline Ciprofloxacin & 3 & 15.8 & 0 & 0 & 4 & 21.1 & 5 & 27.8 & 5 & 26.3 & 2 & 11.1 & 5 & $\begin{array}{l}26 \\
.3\end{array}$ & 6 & 33.3 & 2 & 10.5 & 5 & 27.8 \\
\hline Meropenem & & & & & & & 5 & 33.3 & & & 6 & 40 & & & 2 & 13.3 & & & 2 & 13.3 \\
\hline Imipenem & & & & & & & 6 & 28.6 & & & & 5 & $\begin{array}{l}23 \\
.8\end{array}$ & & 5 & 23.8 & & & 5 & 23.8 \\
\hline Amikacin & & & & & 7 & 25.9 & 2 & 28.6 & 6 & 22.2 & 0 & 0 & 9 & $\begin{array}{l}33 \\
.3\end{array}$ & 3 & 42.9 & 5 & 18.5 & 2 & 28.6 \\
\hline Gentamycin & 3 & 12 & 1 & 5.3 & 7 & 28 & 6 & 31.6 & 7 & 28 & 3 & 15.8 & 5 & 20 & 6 & 31.6 & 3 & 12 & 3 & 15.8 \\
\hline $\begin{array}{l}\text { Amoxicillin+ } \\
\text { clavulanic } \\
\text { acid }\end{array}$ & 2 & 20 & 0 & 0 & 1 & 10 & $\begin{array}{l}1 \\
0\end{array}$ & 47.6 & 5 & 50 & 6 & 26.8 & 1 & 10 & 1 & 4.8 & 1 & 10 & 4 & 19 \\
\hline
\end{tabular}

$\S \mathrm{R}$ refers to resistance and S sensitivity of the bacterial spp. versus tested antibiotics

Table 4: Bacterial isolates and treatment outcomes among DFU patients.

\begin{tabular}{|c|c|c|c|c|}
\hline \multirow{2}{*}{ Isolate } & \multicolumn{2}{|c|}{ §Surgical removal of body part } & \multicolumn{2}{|c|}{ Debridement } \\
\hline & $\mathbf{N}$ & $\%$ & $\mathbf{N}$ & $\%$ \\
\hline Staphylococcus species & 3 & 33.3 & 6 & 66.7 \\
\hline Escherichia coli & 8 & 53.3 & 7 & 46.7 \\
\hline Proteus species & 8 & 66.7 & 4 & 33.3 \\
\hline Pseudomonas aeruginosa & 11 & 78.6 & 3 & 21.4 \\
\hline Others & 9 & 75.0 & 3 & 25.0 \\
\hline
\end{tabular}

§Any loss of limb or part of it due to a patient undergoing either some form of major limb amputation (above or below knee amputation) or disarticulation of digits

\section{DISCUSSION}

Sixty patients were recruited in the study. Thirty-five $(58.33 \%)$ were males. Total number of isolates was 62. The most prevalent isolates were E. coli 15/62 (24.2\%) followed by Pseudomonas aeruginosa 14/62 (22.6\%) Proteus spp. 12/62 (19.4\%) and then Staphylococcus spp. $9 / 62(14.52 \%)$. Other isolates occurred in small numbers such as Acinetobactor spp. 1/62 (1.61\%), Citrobacter spp. 1/62 (1.61\%), Klebsiella pneumonia 4/62 (6.45\%), Streptococcus spp. 4/62 (6.45\%), Morganella morgani $1 / 62(1.61 \%)$ and non-fermenting gram negative bacilli $1 / 62(1.61 \%)$ whose prevalence was collectively $12 / 62$ $(19.3 \%)$. Our results are similar to a study in India where the most common gram-positive cocci in order of frequency were Staphylococcus aureus (17\%), Streptococcus spp. (6\%) and Enterococci spp. (5.0\%). Escherichia coli (20\%) was the predominant isolate followed by Pseudomonas spp. (18\%), Klebsiella spp. (10\%), Proteus spp. (6.0\%) and Acinetobacter spp. (3\%) in gram negative bacilli. However, the Indian study had coagulase negative Staphylococcus (CONS) prevalence of $12 \%$ which is double our prevalence. This discrepancy may be due to the fact that the Indian study had 148 isolates which is more than twice the number of our isolates. $^{21}$ The source of infection, use of antibiotic drug for treatment, sample collection method, and different 
types of infection can influence pathogen diversity in DFI. $^{22}$

From 60 patients with infected DFU in this study, a single bacterial isolate was isolated from $47(78.33 \%)$ patients, 6 $(10.00 \%)$ had two isolates, $1(1.67 \%)$ had three isolates and $6(13.04 \%)$ had no bacterial growth. Although we did not perform regression analyses on the association between multiple isolates and treatment outcome due to low numbers, our data indicates adverse outcome with multiple isolates. For instance, of all patients with multiple isolates $4 / 7(57.14 \%)$ ended up with some form of major limb amputation. This poor prognosis may be explained by the fact that diabetes is an immune suppressive disease and multiple bacterial infection indicates poor glycemic control. ${ }^{23}$ We observed a similar finding in Egypt where a study showed predominance of single bacterial isolate in $52 \%$ of the cultures, $40 \%$ with mixed infections and $8 \%$ with sterile growth. ${ }^{24}$ However, a Nigerian study showed a different observation where there was a predominance of multiple bacterial infections of approximately $71.2 \%$, which is higher than our findings. ${ }^{25}$ There are, however, situations where single and multiple isolates occur in the same proportions. This was the case in India where the proportion of multiple isolates was 48/108 (44.4\%), single isolates was $48 / 108(44.4 \%)$, and no growth in $12 / 108$ $(11.1 \%){ }^{26}$

Majority of the bacterial isolates were gram negative and were multi-resistant. Of the 49/62 (79.3\%) gram negative isolates, $8(16.33 \%)$ were monoresistant, 30 (61.22\%) were multi-resistant, and $11(22.45 \%)$ were susceptible. Of the multi-resistant isolates, Escherichia coli 12/15 (80.00\%), and Pseudomonas aeruginosa 7/14 (50.00\%) were predominant. Of the $13 / 62(20.97 \%)$ Gram positive isolates, $2(15.38 \%)$ were monoresistant, 3 (23.08\%) were multi resistant, and $8 / 13(61.54 \%)$ were susceptible. Studies have identified factors responsible for multiresistance to be frequent hospitalization, recent use of broad-spectrum antibiotics, inadequate surgical source reduction, chronic wounds, irrational use of antibiotics, and the transfer of resistance genes by transport means. ${ }^{22}$ A high level of multi drug resistance could be due to the fact that in a tertiary care hospital there is a widespread usage of broadspectrum antibiotics leading to selective survival advantage of pathogens, a phenomenon called antibiotic selection pressure. ${ }^{27}$

In this study, more than a half of the isolates $17 / 25(68 \%)$ were resistant to ceftriaxone. This is unarguably a high resistance level to a third-generation cephalosporin class of antibiotics. Ceftriaxone has been, over time, excessively and inappropriately prescribed in hospital settings in Tanzanian hospitals. ${ }^{28}$ It is the non-chalant use of this important class of antibiotics that has resulted to such a high level of bacterial resistance against ceftriaxone. Our data have shown, however, that the next higher level of antibiotic use, carbapenems, are still very useful where the bacterial resistance against carbapenems were very low. Imipenem resistance was $1 / 21(4.76 \%)$ and meropenem
1/15 (6.67\%). Carbapenem use in Tanzania is still low currently. However, with such increasing trend of ceftriaxone resistance, carbapenem use is likely to occur. In the face of lack of new molecules from pharmaceutical companies in the last three decades, we risk reverting to a pre-antibiotic era after running out of therapeutic options. $^{4,29}$ To reverse this trend, we need to practice a judicial use of antibiotics by promoting hospital antimicrobial stewardship programs..$^{30-32}$ Hospital antimicrobial stewardship programs cannot be over emphasized to mitigate escalation of antimicrobial resistance. ${ }^{33}$ A similar observation was done in Mwanza, Tanzania where isolates showed high resistance to commonly used antibiotics (such as ampicillin, augmentin, cotrimoxazole, tetracycline, penicillin, gentamicin, erythromycin, oxacillin) except for meropenem and imipenem, which were both $100 \%$ sensitive. ${ }^{34}$ The low resistance to carbapenems is similarly observed in India where sensitivity to imipenem, meropenem were high; imipenem (89\%) and meropenem (84\%). ${ }^{22}$ An important decision is not to switch to carbapenems but make a judicial use of antimicrobials, through antimicrobial stewardship programs, to mitigate escalation of antimicrobial resistance.

With special reference to Pseudomonas aeruginosa, in this study, 14/62 (22.58\%) were isolated and of the tested isolates $7 / 14(50.00 \%)$ were multi-resistant to the tested antibiotics and 2/14 (14.29\%) were monoresistant. As high as $11 / 14(78.57 \%)$ of patients from whom Pseudomonas aeruginosa were isolated ended up having a major limb amputation. Two Indian studies show that pseudomonal control requires "reserve" antibiotics that are not routinely available in hospital settings in Tanzania as essential drug list. One study showed that $15(83.3 \%)$ Pseudomonas aeruginosa strains were susceptible to cefotaxime with a resistance rate of $(16.6 \%) .{ }^{35}$ Another showed that Pseudomonas culture isolates were sensitive to amikacin (90\%), imipenem (72\%), meropenem (70\%), and piperacillin-tazobactam combination $(74 \%) .^{22}$

With regard to some form of major limb amputation or surgical removal of body parts, Pseudomonas aeruginosa had the highest number of isolates 11/14 (78.57\%) followed by Escherichia coli 7/15 (46.67\%). A major problem in Pseudomonas aeruginosa infection may be that this pathogen exhibits a high degree of resistance to a broad spectrum of antibiotics because of its ability (intrinsic) to produce $\beta$-lactamases, efflux pumps, outer membrane modification, and biofilm lifestyle thus making it a dangerous and dreaded pathogen. Most infections with Pseudomonas spp. occur in compromised hosts. ${ }^{35}$ The high rate of amputations among patients from whom Pseudomonas aeruginosa was isolated might be due to its ability to cause severe tissue damage in diabetics, its inherent resistance mechanism, referred to as intrinsic resistance and its multiplicity in resistance mechanisms. ${ }^{35}$ Our data indicate how difficult it is to treat a diabetic patient with an ulcer infected by Pseudomonas. Being nosocomially acquired, hospital infection prevention and 
control (IPC) is a mandatory component of mitigation of antimicrobial resistance. ${ }^{36}$ This study commands some strengths in showing an adequate description of the microbiological isolates with reference to treatment outcome. It describes a clinical picture of the different spectrum of bacterial infection complications in relation to the type of organism isolated from a diabetic foot ulcer.

\section{Limitations}

This study had some limitations in that data was collected for only six months duration of which only 60 patients could be recruited into the study. Diabetic foot ulcer infections admissions are about 7 patients per month. This fact rendered us only able to perform descriptive analysis of the data. Anaerobic and fungal microbiological cultures were not performed in this study. The method used in collecting the specimens was only deep pus swabs. Patients who were enrolled in this study at KCMC as a tertiary care centre might have been exposed to prior antibiotic treatment at primary/peripheral centers.

\section{CONCLUSION}

The most common isolates were gram negatives aerobes, with Escherichia coli and Pseudomonas aeruginosa being the most isolated species. Staphylococcus aureus was the most isolated gram-positive species. More than three quarters of patients with $P$. aeruginosa infection had some form of major limb amputation. For gram negative spp the most effective antibiotic was amikacin, imipenem and meropenem.

Ciprofloxacin, sulfamethoxazole/trimethoprim and gentamicin showed limited effectiveness. Ceftriaxone, a commonly used antibiotic in our settings, showed poor effectiveness. All cases of DFU infection should therefore be subjected to culture and antibiogram sensitivity testing for targeted infection management. In situations where culture and sensitivity pattern data are not available amikacin, imipenem and meropenem can be given as broad-spectrum antibiotics prior to availability of culture and sensitivity results.

These antibiotics have been shown to be highly effective against gram negative aerobes which are the predominant isolates in DFU infections. A larger scale study on DFU should be conducted over a longer duration of time for analytical analysis. Different methods of specimen collection involving pus swabs, tissues biopsy to give a wider picture on the spectrum of bacterial isolates in diabetic foot ulcer are warranted.

\section{ACKNOWLEDGEMENTS}

The authors would like to thank the Executive Director KCMC Hospital, Prof Gileard Masenga for permission to conduct the study at KCMC Hospital, nursing stuff, intern doctors who were rotating at general surgical ward (S1) at the time of the study for their support and assisting in the management of the patients
Funding: The study was funded by Government of United Republic of Tanzania through its Ministry of Health, Community development, Gender, Elderly and Children for Financial Support to conduct the study at Kilimanjaro Christian Medical University College/Kilimanjaro Christian Medical Centre

Conflict of interest: None declared

Ethical approval: The study was approved by the Institutional Ethics Committee

\section{REFERENCES}

1. Soiza RL, Donaldson AIC, Myint PK. Vaccine against arteriosclerosis: an update. Ther Adv Vaccines. 2018;9:259-61

2. Pal S. Diabetic foot complications. U S Pharm. 2014;39.

3. Al-Rubeaan K, Al Derwish M, Ouizi S, Youssef AM, Subhani SN, Ibrahim HM, et al. Diabetic foot complications and their risk factors from a large retrospective cohort study. PLoS One 2015;10:1-17.

4. Aslam B, Wang W, Arshad MI, Khurshid M, Muzammil S, Rasool MH, et al. Antibiotic resistance: a rundown of a global crisis. Infect. Drug Resist. 2018;11:1645-58.

5. Demetriou M, Papanas N, Panagopoulos P, Panopoulou M, Maltezos E. Antibiotic Resistance in Diabetic Foot Soft Tissue Infections: A Series From Greece. Int J Low Extrem Wounds. 2017;16:255-9.

6. Denegre AA, Mbah MLN, Myers K, Fefferman NH. Emergence of antibiotic resistance in immunocompromised host populations: A case study of emerging antibiotic resistant tuberculosis in AIDS patients. PLoS One. 2019;14:1-13.

7. World Health Organization. No time to wait:Securing the future from Drug-resistant infections. 2019. Available at: https://www.who.int/publications-detailredirect/no-time-to-wait-securing-the-future-fromdrug-resistant-infections. Accessed on 24 April 2021.

8. Waglechner N, Wright GD. Antibiotic resistance: It's bad, but why isn't it worse? BMC Biol. 2017;15:1-8.

9. Lomazzi M, Moore M, Johnson A, Balasegaram M, Borisch B. Antimicrobial resistance - Moving forward? BMC Public Health. 2019;19:1-6.

10. Xavier W, Sukumaran MT, Varma AK, Kumar H, Chellan G. Emergence of multi drug resistant bacteria in diabetic patients with lower limb wounds. Indian $\mathbf{J}$ Med Res. 2014;140:435-7.

11. Kreider KE. Diabetes Distress or Major Depressive Disorder? A Practical Approach to Diagnosing and Treating Psychological Comorbidities of Diabetes. Diabetes Ther. 2017;8:1-7.

12. Aljuaid MO, Almutairi AM, Assiri MA, Almalki DM, Alswat K. Diabetes-Related Distress Assessment among Type 2 Diabetes Patients. J Diabetes Res. 2018;7328128.

13. Mama M, Mamo A, Usman H, Hussen B, Hussen A, Morka G. Inappropriate Antibiotic Use Among Inpatients Attending Madda Walabu University Goba 
Referral Hospital, Southeast Ethiopia: Implication for Future Use. Infect Drug Resist. 2020;13:1403-9.

14. Ndihokubwayo J, Yahaya A, Desta A, Ki-Zerbo G, Odei E, Keita B, et al. Antimicrobial resistance in the African Region: issues, challenges and actions proposed. WHO Press. 2013;16:27-30.

15. Lai PS, Bebell LM, Meney C, Valeri L, White MC. Epidemiology of antibiotic-resistant wound infections from six countries in Africa. BMJ Glob Health. 2017;2.

16. Tadesse BT, Ashley EA, Ongarello S, Havumaki J, Wijegoonewardena M, González IJ, et al. Antimicrobial resistance in Africa: A systematic review. BMC Infect Dis. 2017;11:17.

17. United THE, Of R, Health MOF, Development C, Aids N, Programme C. the United Republic of Tanzania the National. 2019. Available at: https://www.imf.org/en/Publications/CR/Issues/2020/ 06/12/United-Republic-of-Tanzania-Request-forDebt-Relief-under-the-Catastrophe-Containmentand-49509.

18. Meseret G, Kassaye A, Yared M. Bacteria from infected surgical wounds and their antimicrobial resistance in Hawassa University Referral Teaching Hospital, Southern Ethiopia. African J Microbiol Res. 2014;8:1118-24.

19. Moremi N, Claus H, Mshana SE. Antimicrobial resistance pattern: A report of microbiological cultures at a tertiary hospital in Tanzania. BMC Infect Dis. 2016;16.

20. Palareti G, Legnani C, Cosmi B, Antonucci E, Erba N, Poli D, et al. Comparison between different D-Dimer cutoff values to assess the individual risk of recurrent venous thromboembolism: Analysis of results obtained in the DULCIS study. Int J Lab Hematol. 2016;38:42-9.

21. Manikandan C, Prabhakaran P. Clinical and bacteriological profile of diabetic foot infections in Pattukkottai area hospitals, Tamilnadu, India. Int J Curr Res Acad Rev. 2015;3:166-73.

22. Jain SK, Rashmisnata B. Bacteriological Profile of Diabetic Foot Ulcer with Special Reference to Drugresistant Strains in a Tertiary Care Center in NorthEast India. Indian J Endocrinol Metab. 2017;21:76575.

23. Casqueiro J, Casqueiro J, Alves C. Infections in patients with diabetes mellitus: A review of pathogenesis [Internet]. Indian J Endocrinol Metab. 2016;16:1-15.

24. Al-Hamead Hefni A, Ibrahim AR, Attia KM, Moawad MM, El-ramah AF, Shahin MM, et al. Bacteriological study of diabetic foot infection in Egypt. Arab Soc Med Res. 2013;8:1687-4293.

25. Anyim O, Okafor C, Young E, Obumneme-Anyim I, Nwatu C. Pattern and microbiological characteristics of diabetic foot ulcers in a Nigerian tertiary hospital. Afr Health Sci. 2019;19:1617-27.
26. Sekhar S, Vyas N, Unnikrishnan M, Rodrigues G, Mukhopadhyay C. Antimicrobial susceptibility pattern in diabetic foot ulcer: A pilot study. Ann Med Health Sci Res. 2014;4:742.

27. Gadepalli R, Dhawan B, Sreenivas V, Kapil A, Ammini AC, Chaudhry R. A clinico-microbiological study of diabetic foot ulcers in an Indian tertiary care hospital. Diabetes Care. 2006;29:1727-32.

28. Sonda TB, Horumpende PG, Kumburu HH, van Zwetselaar M, Mshana SE, Alifrangis M, et al. Ceftriaxone use in a tertiary care hospital in Kilimanjaro, Tanzania: A need for a hospital antibiotic stewardship programme. PLoS One. 2019;14.

29. Agrawal C, Madan M, Pandey A, Chauhan H, Qureshi S. Superbugs causing ventilator associated pneumonia in a tertiary care hospital and the return of preantibiotic era! Indian J Med Microbiol. 2015;33:286.

30. Sonda TB, Horumpende PG, Kumburu HH, van Zwetselaar M, Mshana SE, Alifrangis M, et al. Ceftriaxone use in a tertiary care hospital in Kilimanjaro, Tanzania: A need for a hospital antibiotic stewardship programme. PLoS One. 2019; 14:e0220261.

31. Mshana SE, Matee M, Rweyemamu M. Antimicrobial resistance in human and animal pathogens in Zambia, Democratic Republic of Congo, Mozambique and Tanzania: an urgent need of a sustainable surveillance system. Ann Clin Microbiol Antimicrob. 2013;12(12):28.

32. Tellevik MG, Blomberg B, Kommedal $\varnothing$, Maselle SY, Langeland N, Moyo SJ. High prevalence of faecal carriage of esbl-producing enterobacteriaceae among children in Dar es Salaam, Tanzania. PLoS One. 2016;1:11.

33. Schuts EC, Hulscher MEJL, Mouton JW, Verduin CM, Stuart JWTC, Overdiek HWPM, et al. Current evidence on hospital antimicrobial stewardship objectives: a systematic review and meta-analysis. Lancet Infect Dis. 2016;16:847-56.

34. Chalya PL, Mabula JB, Dass RM, Kabangila R, Jaka $\mathrm{H}$, Mchembe MD, et al. Surgical management of Diabetic foot ulcers: A Tanzanian university teaching hospital experience. BMC Res Notes. 2011;4:365.

35. Sivanmaliappan TS, Sevanan M. Antimicrobial susceptibility patterns of pseudomonas aeruginosa from diabetes patients with foot ulcers. Int $\mathrm{J}$ Microbiol. 2011.

36. Moremi N, Claus H, Mshana SE. Antimicrobial resistance pattern: a report of microbiological cultures at a tertiary hospital in Tanzania. BMC Infect Dis. 2016;13(16):756.

Cite this article as: Shabhay A, Horumpende $\mathrm{P}$, Mujuni M, Munisi EJ, Mshana S, Shabhay Z, et al. Antibiotic resistance in aerobic bacterial isolates from infected diabetic foot ulcers in North Eastern Tanzania: an urgent call to establish a hospital antimicrobial stewardship committee. Int J Basic Clin Pharmacol 2021;10:1163-9. 